\title{
Household labour allocation to forest extraction and other activities in areas adjacent to tropical forests: the case of Kakamega forest, Western Kenya
}

\author{
Geophrey Sikei* \\ African Economic Research Consortium (AERC), \\ PO Box 62882-00200, Nairobi, \\ Kenya \\ Fax: +254-20-273-4170/3 \\ E-mail: geophrey.sikei@aercafrica.org \\ E-mail: goosikei@yahoo.com \\ *Corresponding author

\section{John Mburu} \\ International Livestock Research Institute (ILRI), \\ PO Box 30709-00100, \\ Nairobi, Kenya; \\ Department of Agricultural Economics, \\ University of Nairobi, \\ PO Box 29053-00625, \\ Nairobi, Kenya \\ E-mail: j.mburu@cgiar.org
}

\section{Job Kibiwot Lagat}

Department of Agriculture Economics,

Egerton University,

PO Box 536, Egerton, Nakuru,

Kenya

E-mail: jlagats@yahoo.com

\begin{abstract}
Communities adjacent to forests are faced with a challenge of balancing their labour allocation decisions to the different household activities. This study involves an empirical examination of the determinants of households labour allocation decisions with respect to three different activities identified as important in the study area; agriculture, forest and non-farm. This was done by estimating a labour share model similar to standard models of commodity or factor demand, such as the Almost Ideal Demand Systems (AIDS) model. Data on household characteristics and key policy parameters directly or indirectly affecting labour allocation decisions were collected between March and May 2007. A semi-structured questionnaire was used to collect data from a random sample of 140 households. From the findings, it was evident that household members respond positively to wage returns. The positive relationship between the returns to forest use and forest labour share provides a cautionary message for policy-makers and other stakeholders concerned with the fate of the Kakamega forest. In the short term, it seems
\end{abstract}


probable that the returns to forest use will increase as the aggregate demand for forest products rises and supply declines. The study findings suggest that, with improved economic well-being, households become less reliant on forests for their livelihoods. Since reduced forest reliance is positively related with a reduced demand for forest products, these findings suggest a complementary relationship between strategies aimed at poverty alleviation and those aimed towards forest conservation.

Keywords: labour allocation; labour share; fuelwood collection; Kakamega forest.

Reference to this paper should be made as follows: Sikei, G., Mburu, J. and Lagat, J. (2008) 'Household labour allocation to forest extraction and other activities in areas adjacent to tropical forests: the case of Kakamega forest, Western Kenya', Int. J. Environment, Workplace and Employment, Vol. 4, No. 1, pp.32-44.

Biographical notes: Geophrey Sikei is an Agricultural/Resource Economist currently engaged with the African Economic Research Consortium (AERC) as a Research Assistant/Consultant. He holds an MS degree in agricultural and applied economics (2008) from Egerton University, Kenya, with a specialisation in environmental and resource economics. Prior to joining AERC, He was engaged with the Kenya Institute for Public Policy Research and Analysis (KIPPRA) as a Research Assistant. He has been involved extensively in research works mainly concerned with environment-poverty linkages in Kenya.

John Mburu is an Agricultural/Resource Economist at the International Livestock Research Institute (ILRI) and a Lecturer at the Department of Agricultural Economics, University of Nairobi, Kenya. He holds a PhD degree in Agricultural Economics (2002) from the University of Goettingen, Germany, with a specialisation in environmental and resource economics. He joined the ILRI and the University of Nairobi in June 2007 from the Center for Development Research (ZEF), Bonn, Germany, where he worked as a Senior Research Fellow for almost five years. He has published widely on agricultural and environmental economics, and has acquired extensive experience working in developing countries such as Brazil, Ethiopia, India, Kenya, Malawi, Uganda and Zambia.

Job Kibiwot Lagat is as a Senior Lecturer and Researcher in the Department of Agricultural Economics and Agribusiness at Egerton University, Njoro, Kenya. $\mathrm{He}$ is qualified with a $\mathrm{PhD}$ degree in agricultural and resource economics and teaches and supervises graduate students. He is the Executive Editor of the newly established International Journal of Applied Agricultural Economics and Agribusiness. His research interests are resource and environmental economics.

\section{Introduction}

In developing countries, forests provide many products and services to rural populations. These include wood for fuel, fodder for livestock and building materials, among others. While forest use is nearly ubiquitous in the developing world, the degree of forest dependence varies considerably across households. For some rural households, forests are a main source of livelihood; for others, they serve primarily a supplementary role or as a safety net in difficult times (Warner, 2000). 
In Kenya, forests occupy a paltry $2.8 \%$ of the total land area (Byron and Arnold, 1999). Despite this relatively small forest cover, there is a high dependence on forest for the provision of wood and non-wood products. As noted by Mogaka et al. (2001), it is estimated that about 3 million people living adjacent to forests in Kenya depend heavily upon them for the provision of wood and non-wood products needs. Most of these populations are often found in rural areas characterised by a biomass-based economy in which local land resources provide for the bulk of their survival needs.

The Kakamega forest in Western Kenya is one such forest where rural dependence has always remained relatively high. The forest has elicited a great deal of attention due to its uniqueness; it is the only patch of Guineo-Congolean rainforest remaining in Kenya - a forest type that spans much of West and Central Africa. The forest is also located in one of the world's most densely populated rural areas, with an average population density of 600 people per square kilometre (Blackett, 1994). A rapidly growing population occupying 57 forest-adjusted villages places great pressure upon the Kakamega forest (KIFCON, 1994). Population growth is resulting in repeated subdivision of land parcels which, along with the growing pressure to continually cultivate all the available land, has rendered the traditional agricultural system of fallow rotation almost unworkable. As a result, the forest has become an ever more important source for satisfying the daily needs of the local people. Hunting, collecting of medicinal plants, charcoal burning, illegal pit-sawing, grazing, collecting of fuelwood and the agricultural shamba-system are some of the threats to which the forest is exposed (Mitchell, 2004).

As a consequence of the continuing decline of the forest, rural economies are forced to harness a combination of strategies for adaptability purposes. Key among them is the critical decision of how to allocate their constrained labour to the different productive activities within the household. Studies by Cooke (1998), among others, have noted that, in the face of scarcity, households will allocate more labour to the collection of environmental products at the expense of other productive activities. Factors influencing such labour allocations are poorly understood. In addition, it is believed that women bear the increased burden of forest products scarcity by having to contribute much of the extra labour that is needed. It is against this background that the present study was prompted and initiated.

The main objective of this paper is to determine the factors influencing the labour allocation decisions of rural households within Kakamega - i.e. the allocation of labour between forest-related and other productive activities. This is crucial to formulating policies that can improve the welfare of smallholders, particularly given the dependence of rural households on forest resources and the uppermost concern of this issue to policy-makers. If it turns out that labour allocation decisions are influenced by the existence of forest products, a strong case can be presented for the protection of these resources. Projects that allow households to save time by increasing the availability of environmental products or by allowing more efficient use of them may also prove to be very beneficial.

\section{The theoretical framework used}

This study draws upon the economic theory of farm households as explained by Singh et al. (1986). The model considers the non-separable and interdependent characteristics of many low-income farm households, and also the weak markets for key factors and 
products. This interdependency assumption and the non-separatability associated with it implies that household resource allocation - which includes forest product supply and demand, and on-farm and off-farm labour allocation - is decided simultaneously, rather than recursively (Heltberg et al., 2000).

The study also considers households living adjacent to a forest. Members of the household are assumed to engage in agricultural activities, forest gathering activities and non-agriculture/non-forest activities. The household maximises utility by choosing to allocate labour to specific activities, consumption and inputs. The household solves:

$$
\operatorname{Max}_{L, C_{i}, X} U=U\left(C_{j}, N ; H\right), \quad j=a, f, n
$$

where

- utility $U$ is derived from the consumption of an agricultural commodity $\left(C_{a}\right)$

- $\quad$ forest product is $\left(C_{f}\right)$

- $\quad$ non-farm (non-forest) good is $\left(C_{n}\right)$

- leisure is $(N)$

- $\quad H$ are household characteristics influencing preferences.

Household leisure time is not modelled as the labour-leisure margin in most rural households is assumed to be negligible (Adhikari, 1996). The household maximises utility subject to the following production function for agricultural commodities:

$$
Q_{a}=Q_{a}\left\{L_{a}, X, A_{O}\right\}
$$

where $Q_{a}$ is agricultural production, which is assumed to be a function of labour $L_{a}$, purchased inputs (e.g. fertiliser $X$ ) and the household's land endowment $A_{O}$. Households use their own male and female labour for agricultural production, and may also hire both male and female labour. Labour hired of the same gender and own-household labour inputs are assumed to be perfectly substitutable, although male labour and female labour in general do not serve as substitute forms of labour. The households are also assumed to be risk averse.

Similarly, the production function for forest product is:

$$
Q_{f}=Q_{f}\left(L_{f}, F\right)
$$

where

- $Q_{f}$ describes the production of forest goods

- $\quad L_{f}$ is the household's labour in extracting forest product

- $F$ is the distance to the forest.

The production function for non-farm/non-forest goods, which require only labour $\left(L_{n}\right)$ for production, is given by: 


$$
Q_{n}=Q_{n}\left(L_{n}\right)
$$

The household's budget constraint is defined as:

$$
Y=\sum_{j}\left[\left(p_{j} Q_{j}-p_{j} C_{j}\right]-p_{X} X+v L_{V}\right.
$$

Households are assumed to engage in a competitive market for agricultural products where they can sell and buy at market prices $p_{i}$ that are assumed to be exogenous. Farm inputs $(X)$ are purchased but not sold. The household may also buy and/or sell household labour at the market wage rate of $v$, although the labour market is assumed to be thin.

The household's time constraint therefore becomes:

$$
T-N=\sum_{j} L_{j}
$$

The Lagrangian of the household's maximisation problem is:

$$
L=U\left(C_{j}, T-\sum_{j} L_{j}: H\right)+\lambda\left[\begin{array}{l}
{\left[p_{a} Q_{a}\left(L_{a}, X, A_{O}\right)-p_{a} C_{a}-p_{X} X\right]+\left[p_{f} Q_{f}\left(L_{f}, F\right)\right.} \\
\left.-p_{f} C_{f}\right]+\left[p_{n} Q_{n}\left(L_{n}\right)\right]
\end{array}\right]
$$

whose expressions after rearranging become:

$$
\begin{aligned}
& \frac{\partial U(\cdot)}{\partial C_{a}}=\lambda p_{a} \\
& \frac{\partial U(\cdot)}{\partial C_{f}}=\lambda p_{f} \\
& \frac{\partial U(\cdot)}{\partial C_{n}}=\lambda p_{n} \\
& \frac{\partial U(\cdot)}{\partial N}=\lambda p_{a} \frac{\partial Q_{a}(\cdot)}{\partial L_{a}} \\
& \frac{\partial U(\cdot)}{\partial N}=\lambda p_{a} \frac{\partial Q_{a}(\cdot)}{\partial L_{a}} \\
& \frac{\partial U(\cdot)}{\partial N}=\lambda p_{n} \frac{\partial Q_{n}(\cdot)}{\partial L_{n}} \\
& p_{a} \frac{\partial Q_{a}}{\partial X}=p_{X} \cdot
\end{aligned}
$$

Note that, at equilibrium, the ratios of the marginal products of $C_{a}, C_{f}$ and $C_{n}$ will equalise with their price ratios. Equations (8d)-(8f) indicate that, at the optimum, households allocate labour across activities so as to equate the marginal value of 
household leisure with that of time spent on each productive activity. Expressions for labour supply, input demand and commodity demand can be derived as functions of all exogenous variables; $p_{i}, H, A_{O}, F, T$.

\section{Materials and methods}

\subsection{Study area}

The study site for this survey was an area around the Kakamega forest, situated in the Kakamega District in the Western Province of Kenya (Figure 1). It lies north-east of Lake Victoria between latitudes $00^{\circ} 10^{\prime} \mathrm{N}$ and $00^{\circ} 21^{\prime} \mathrm{N}$ and longitudes $34^{\circ} 47^{\prime} \mathrm{E}$ and $34^{\circ} 58^{\prime} \mathrm{E}$ at about 1600 metres above sea level.

Figure 1 Kakamega forest and its environs

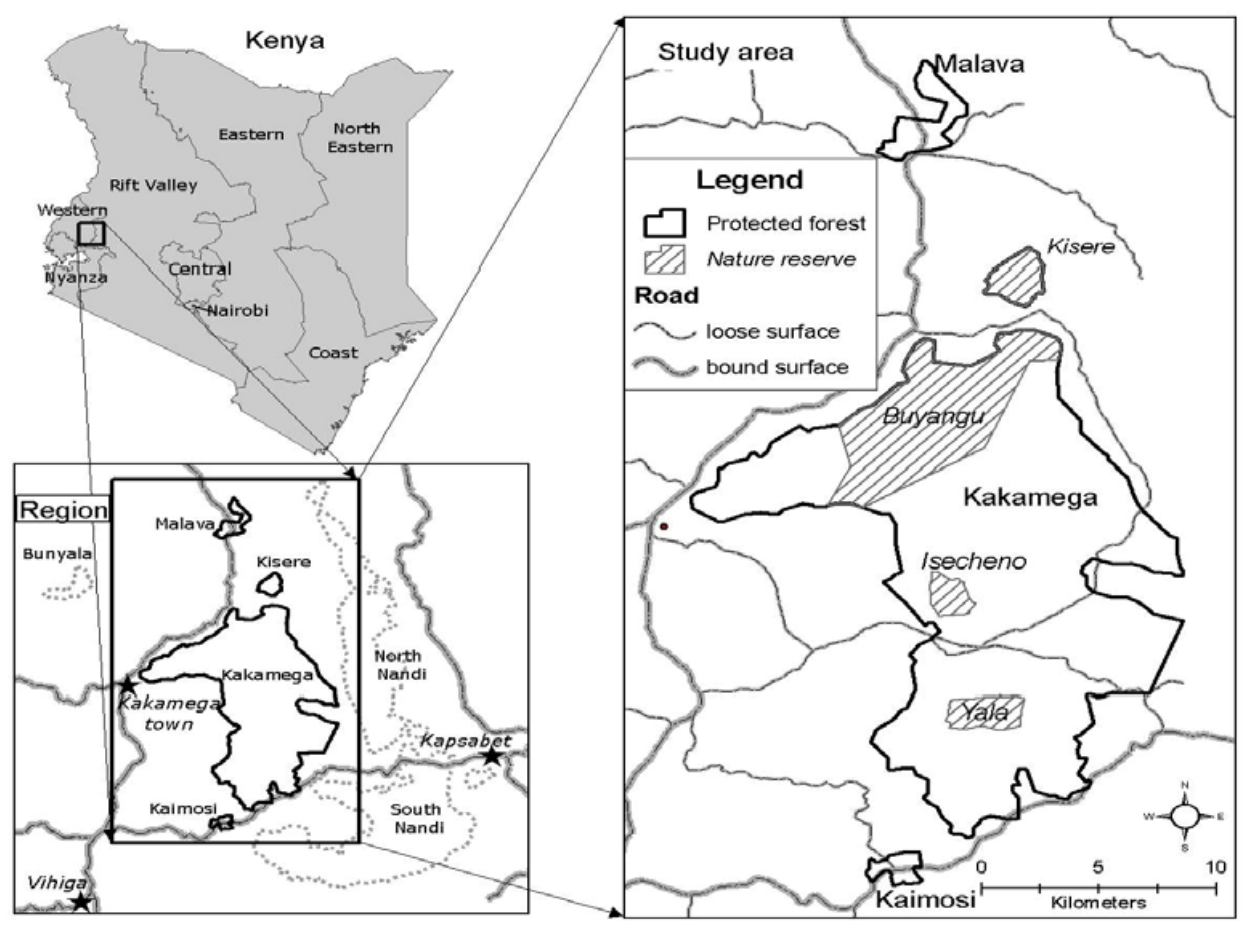

The forest covers an area of about 154.8 square kilometres out of which 15.92 square kilometres is plantation forest while the rest is natural forest. The 1994 welfare monitoring survey carried out in Kenya showed that $52 \%$ of the population in the district lie below the poverty line meaning that they have difficulties affording basic necessities such as food, shelter, clothing, education and other like amenities (Government of Kenya, 2002). The Kakamega forest houses unique biological resources (flora, fauna and avifauna), which share similar characteristics with those of the Western African equatorial rainforests. 


\subsection{Livelihood activities in the study area}

Within the study area, the majority of its inhabitants are employed in the agricultural sector (Government of Kenya, 2002). Most are small-scale farmers. In fact, $80 \%$ of the population lives in rural areas, and $62 \%$ of all households generate their income from agriculture. At the same time, the district suffers from extreme demographic pressure with an annual population growth rate of $2.12 \%$. Therefore, with $76 \%$ of the district's area under agricultural cultivation and an additional $11 \%$ being covered with (gazetted) forest, an extension of cultivated areas seems impossible. This fact, combined with a district poverty rate of $52 \%$, shows the importance of exploring ways to facilitate secure incomes for households dependent on small-scale farming.

Studies by among others, such as Guthiga and Mburu (2006), have showed widespread dependence on the forest by the local people who obtain firewood, thatch grass and medicinal plants from the forest. The forest is also used for grazing purposes. Incidences of illegal logging, charcoal burning and animal hunting are also common. All these activities add-up to the daily livelihood engagements of the peasants. The current study, however, found that labour markets for forest products are dysfunctional or thin. For instance, the main forest product - fuelwood - attracted no standard unit price in all the zones visited. This prompted us to use a derived shadow price approach to obtain the market value of fuelwood.

\subsection{Data collection and analysis techniques}

Data used for this study was collected from study sites for the BIOdiversity Monitoring Transect Analysis in East Africa (BIOTA-EA) Subproject E13 between March and May 2007. The target population involved households living within approximately a 5 kilometre radius of the forest. The distance was purposely chosen for convenience since an earlier reconnaissance survey indicated that progressively fewer people extract products beyond the 5 kilometre radius (Guthiga and Mburu, 2006). A census of households carried out with the help of administrative village heads and other local leaders generated a sampling frame consisting of approximately 34,000 households residing within approximately a 10 kilometre radius of the forest. A random sample of 378 households was generated. The sampled households were randomly interspersed in the study area and across three management regimes. The three management regimes in the Kakamega forest are the Kenya Wildlife Service (KWS), the Forest Department (FD) and the Quakers Church Mission (QCM). From the random sample generated by the project, a total of 140 households were selected. Semi-structured questionnaires were used to elicit information on households' socioeconomic characteristics, own-farm, forestry and other off-farm activities.

\subsection{Empirical methods}

The empirical model used to analyse determinants of labour allocation within households is indicated below. Labour shares were taken as the dependant variables. The model is a system of three jointly estimated labour share equations (for fuelwood collection, agriculture and non-farm activities) where each labour share is a function of the variables indicated in the household model discussed in the theory section. The model takes the form: 


$$
L_{i j}=\alpha_{i}+\sum_{j} \beta_{i j} L O G\left(P_{j}\right)+\eta_{i} K+\gamma_{i} E+\chi_{i} A_{o}+\delta_{i} F+\psi_{i} S+\mu_{i} G+\varepsilon_{i}
$$

where

- $\quad$ subscripts $i$ represents individual households

- $\quad j$ represents activities undertaken

- $\quad L$ is the labour share per activity

- $P_{j}$ are the labour returns from each activity

- $\quad K$ is the age of the household head

- $E$ is the education level of the household head

- $A_{O}$ is the size of landholding

- $F$ is the distance to the forest

- $S$ is the household size

- $G$ is the gender of the household involved

- $\varepsilon_{i}$ is the error term.

The labour share model is similar to standard models of commodity or factor demand; for example, the Almost Ideal Demand Systems (AIDS) model developed by Deaton and Muellbauer (1980).

Not unlike the AIDS model, the parameters of the labour share system are constrained across equations. If the system of equations is complete, then, by construction, the observed labour shares will sum to one. In order to ensure that predicted labour shares also sum to one, the following restrictions are imposed:

$$
\begin{aligned}
& \sum_{j} \beta_{i j}=0 \\
& \sum_{j} \eta_{i}=0, \quad \sum_{j} \gamma_{i}=0, \quad \sum_{j} \chi_{i}=0, \quad \sum_{j} \delta_{i}=0, \quad \sum_{j} \psi_{i}=0 \quad \text { and } \sum_{j} \mu_{i}=0 \\
& \sum_{j} \varepsilon_{i}=0 \\
& \alpha_{a}+\alpha_{f}+\alpha_{n}=1 .
\end{aligned}
$$

The homogeneity restriction of equation (10) implies that a given labour share is invariant to proportional changes in all prices. Constraint (11) requires that the individual effects of changes in explanatory variables on labour allocation are offsetting such that the net effect of a change in a given explanatory variable on labour allocation is zero. Constraint (12) requires error terms across equations to be linearly dependant; and constraint (13) combined with the so-called adding-up restrictions ensures that the estimated labour shares sum to one. While an OLS estimate of these equations would be consistent and unbiased, the estimation method developed by Zellner (1962) for 
Seemingly Unrelated Regressions (SURE) provides estimates that are more efficient. During estimation, one of the equations is dropped from the model to avoid singularity of the disturbance covariance matrix (Sadoulet and de Janvry, 1995).

\section{Results and discussions}

Table 1 provides descriptive statistics for the variables used in the model. An iterative SURE which provides estimates that are invariant to the dropped equation was used in estimating the labour share equations. In controlling for sample selection bias, the inverse Mills ratio was generated for each household before estimation. The ratio was then additively included as a regressor in the subsequent share equations. This was undertaken to ensure correction for selectivity bias in cases where no observations were made. The inverse Mills ratio was not statistically significant in any of the equations which suggests that the sample selection bias was not an issue.

Table 1 Descriptive statistics for variables used in the model

\begin{tabular}{|c|c|c|}
\hline Variable & Variable definition & Mean (standard deviation) \\
\hline$P_{f}$ & Imputed shadow wages for forest activities & $2.553(1.903)$ \\
\hline$P_{a}$ & Imputed shadow wages for agricultural activities & $3.060(2.767)$ \\
\hline$P_{n}$ & Imputed shadow wages for off-farm activities & $5.276(0.185)$ \\
\hline$K$ & Age of household head in years & $51.126(15.373)$ \\
\hline$E$ & $\begin{array}{l}\text { Education level of head in terms of numbers of } \\
\text { years spent schooling }\end{array}$ & $7(4.254)$ \\
\hline$A_{O}$ & Size of landholding held by household & $3.369(2.926)$ \\
\hline$F$ & Distance to the forest & $2.431(1.763)$ \\
\hline$S$ & Household size & $5.244(2.135)$ \\
\hline$G$ & Gender of household collecting & $0.757(0.430)$ \\
\hline
\end{tabular}

Source: Survey data (2007)

The results presented in Table 2 show the factors influencing households' allocation of labour to different activities. The imputed shadow wage from forest activities reveals a positive relation with the forest labour share. Similarly, labour returns from farm and off-farm activities show a positive relation with their respective labour shares. However, cross-wage effects between the different activities are negatively related. The positive signs on an activity's labour returns in the labour share equations indicate that the households obtaining higher returns from a particular activity will allocate a greater share of household labour to the activity, and vice versa. These findings are consistent with those advanced by among others Bagamba et al. (2007) and Shively et al. (2005) who have showed that rural households respond positively to increased shadow wages - that is, rural agricultural households make decisions largely based on returns from a particular activity. 
The case of Kakamega forest, Western Kenya

Table 2 Estimation results for the labour share equations

\begin{tabular}{lccc}
\hline Constant & Forest labour share & Agricultural labour share & Non-farm labour share \\
\hline$P_{f}$ & -0.106 & 0.475 & 0.631 \\
$P_{a}$ & $0.001^{* *}$ & 0.001 & -0.035 \\
$P_{n}$ & 0.001 & $0.028^{*}$ & $-0.028^{*}$ \\
$K$ & -0.035 & $-0.028^{*}$ & 0.082 \\
$E$ & 0.002 & -0.001 & -0.001 \\
$A_{O}$ & $-0.005^{* *}$ & $0.013^{*}$ & $-0.008^{* *}$ \\
$F$ & $-0.005^{*}$ & $0.014^{*}$ & -0.009 \\
$S$ & -0.002 & 0.001 & 0.001 \\
$G$ & $0.008^{* *}$ & $-0.018^{*}$ & 0.010 \\
\hline
\end{tabular}

Notes: $\quad *$ implies significant at $5 \%$ level; $* *$ significant at $10 \%$ level.

Source: Survey data (2007)

The effect of age on labour shares is statistically insignificant. However, results show that age is positively related to the forest share of labour while negatively related to farm and off-farm shares. The elderly tend to spend more time in forest activities. The young and middle-aged persons, who together comprise the majority of the most productive labour in many rural set-ups, tend to engage in other productive activities, such as farming and off-farm employment, as well as forest activities.

The effect of education is negative in terms of forest labour share, positive in terms of the agricultural labour share and negative in terms of the non-farm labour share. The variable is significant in all cases. In relation to the forest sector, a plausible explanation is that education sends a signal to employers about workers' potential productivity, thereby increasing the chances of educated people being hired into attractive non-farm, non-forest activities that, in turn, reduce the allocation of educated labour to the less remunerative forest sector. This finding is in line with Gunatilake's (1998) conclusion that the education level of the family is negatively related to forest dependency. The result for non-farm labour, however, contradicts what is widely assumed. Normally, it is expected that educated workers will find high-paying jobs, locally or in secondary cities (World Development Report, 2008). In attempts to explain this contradiction, we follow the lines of Buchenrieder (2003) in his study of rural households in Russia. Buchenrieder argues that, in the rural set-up, there exists numerous menial opportunities of non-farm self-employment, an assumption which is also true for rural Kakamega. As a result, better educational attainment had a negative effect on the likelihood of engaging in non-farm activities in the Russian sample, since the better educated tended to follow the demand-pull process and look for more remunerative occupations. Another plausible explanation for the contradiction is that, in rural Kakamega, off-farm activities performed by farmers themselves are more traditional which do not require any formal education. Woldehanna (2000) support this argument in his study in Ethiopia. 
The effect of landholding on the forest share is negative and significant; positive and significant in the agricultural share and negative but insignificant in the non-farm share. Matshe and Young (2004) also found farm size negatively related to amount of time allocated to off-farm activities. Plausible explanations are that households with large parcels of land concentrate most of their labour on farms relative to forest and non-farm activities. This variable increases agricultural output and hence the marginal value of farm labour. When the marginal value of farm labour increases, households substitute farm work for off-farm and forest work (a substitution effect).

The forest distance reveals a negative and insignificant effect on the forest share of labour. As distance to the forest increases, households will tend to reduce the labour allocated to fuelwood search and/or turn to fuelwood collection around the homesteads. These findings are consistent with those obtained by Cooke (1998) and Amacher et al. (1996) in Nepal. Distance is positively related to the agricultural and non-farm shares of labour. The additional time that is spent getting to the forest is increasingly allocated to other productive activities like farming or off-farm endeavours.

The size of families is more directly related to household members' participation in different activities and household production. Household size has significant effects on the forest and agricultural labour shares. It is positively related to the forest share of labour while being negative for agriculture. A family with a larger labour force can mobilise household labour in forest extraction activities more so than households with a smaller labour force. There is no restriction on the number of people from a single household who can harvest such products. In this case, households with more members tend to collect a larger portion of forest products, more so because their consumption of fuelwood is generally high. The household size has no significant effect on the non-farm labour share, although it is positive. Larger families supply more labour to the rural non-farm sector given that it is easier for a sufficient number of family members to remain in the home or on the farm to meet subsistence needs. However, it is important to note that the economic rationing of hired labour is influenced more by market wages than family size and composition. Household size is also negatively related to the agricultural share of labour, and statistically significant. A plausible explanation for this is that, as the family becomes bigger, there is a higher probability that some of the family members will be earning some income from non-farm, self-employment activities, as already discussed above.

In order to determine the gender influence on labour allocation to activities within the households, a dummy variable for gender was incorporated into the model. This was prompted by the belief that, in times of labour constraints, women bear the greatest labour burden within households. Results revealed a non-significant gender variable in all the three shares. This implies that gender is a necessary but not sufficient factor to influence how labour is allocated to different activities in rural households. In terms of the forest share of labour, the study findings suggest that women do not necessarily bear the burden of increased scarcity of forest products - in particular, fuelwood collection. This finding is consistent with results generated by Adhikari (1996) and Amacher et al. (1993). One important policy observation drawn from this finding is that women, and by extension children, are not the only labour force engaged in fuelwood collection as purported by many studies. However, the findings contradict those by Abdulai and Delgado (1999) and Newman and Canagarajah (2000) which found that the gender effect on time allocation to farm production was insignificant, and thus concluded that being male increased the chance of working off-farm; but decreased the time allocated to home production activities. 


\section{Conclusion}

In using a systems approach, this study has demonstrated that households will reallocate labour from one activity to the other if returns from the latter exceed the former. Findings reveal that forest use and non-farm wage work are substitute activities for sample households. Higher returns from forest activities increase the forest labour share and simultaneously reduce the non-farm wage work share. Likewise, as returns to wage work rise, households devote a greater share of their labour to paid employment and a lower share to forests. Results further indicate that there is less labour reallocation from agriculture activities. It is quite conceivable that agriculture is such a high priority for subsistence farmers that leisure time or time devoted to other activities will be sacrificed first before agricultural labour time is reduced. These findings have implications for the types of policies needed to support improved labour supply decisions in the rural sector.

Optimistically, the positive own-wage effects in each labour share equation suggest that households respond well to production and work incentives, an essential element in economic development. Likewise, negative cross-wage terms in most equations indicate that labour can be drawn away from one sector through return-incentives in another. It is thus plausible to suggest that public sector investment in off-farm wage work is a potential strategy to reduce forest pressure.

The results have confirmed that education improves the earning capacity of labour in the off-farm sector in Kakamega. The implication of this result is that investment in education would favour the off-farm sector against on-farm and forest employment or activities. Since landholding increases agricultural output, it positively affects the supply of labour to this sector. Policies should therefore be put in place to make it more attractive for rural households to participate in farming activities, since this would help to tackle the unemployment problem rampant in Kakamega and many other parts of Kenya's rural settings.

\section{Acknowledgements}

The authors acknowledge the BIOdiversity Monitoring Transect Analysis in East Africa (BIOTA-EA) Project and the Center for Development Research (ZEF), Bonn, Germany, for providing partial funding for this study.

\section{References}

Abdulai, A. and Delgado, C. (1999) 'Determinants of nonfarm earnings of farm-based husbands and wives in Northern Ghana', American Journal of Agricultural Economics, Vol. 81, pp.117-130.

Adhikari, B. (1996) 'Common property resource management by user groups: an experience from middle hill of Nepal', Proceedings of International Symposium on Geology and Environment, 31 January-2 February, Chinag Mai University, Chiang Mai, Thailand.

Amacher, G., Hyde, W. and Joshee, B. (1993) 'Joint production and consumption in traditional households: fuelwood and crop residues in two districts in Nepal', Journal of Development Studies, Vol. 30, No. 1, pp.206-225.

Amacher, G., Hyde, W. and Kanel, K. (1996) 'Household fuelwood demand and supply in Nepal's tarai and mid-hills: choice between cash outlays and labour opportunity', World Development, Vol. 24, No. 11, pp.1725-1736. 
Bagamba, F., Burger, K. and Kuyvenhoven, A. (2007) 'Determinants of smallholder farmer labour allocation decisions in Uganda', Paper presented at The EAAE Seminar on Pro-Poor Development in Low Income Countries: Food, Agriculture, Trade and Environment, Montpellier, France.

Blackett, H.L. (1994) Forest Inventory Report No. 3, Kakamega Forest Department/KIFCON, Kenya, Nairobi.

Buchenrieder, G. (2003) 'Overview of poverty impacts of and policy options for non-farm rural employment', Proceedings of the Mini-Symposium at the 25th International Conference of Agricultural Economists, Durban, South Africa, University of Hohenheim, Stuttgart, pp.1-23.

Byron, N. and Arnold, M. (1999) 'What futures for the people of the tropical forests', World Development, Vol. 27, No. 5, pp.789-805.

Cooke, P.A. (1998) 'Intra-household labour allocation responses to environmental good scarcity: a case study from the hills of Nepal', Economic Development and Cultural Change, Vol. 46, No. 4, pp.807-830.

Deaton, A. and Muellbauer, J. (1980) 'An almost ideal demand system', The American Economic Review, Vol. 70, No. 3, pp.312-326.

Government of Kenya (2002) Kakamega District Development Plan 2002-2008, Government Printer, Nairobi.

Gunatilake, H. (1998) 'The role of rural development in protecting tropical rainforests: evidence from Sri Lanka', Journal of Environmental Management, Vol. 53, pp.273-292.

Guthiga, P. and Mburu, J. (2006) 'Local communities incentives for forest conservation: case of Kakamega forest in Kenya', Paper presented at the 11th Biannual Conference of International Association for the Study of Common Property (IASCP), Indonesia.

Heltberg, R., Arndt, T. and Sekhar, N. (2000) 'Fulewood consumption and forest degradation: a household model for domestic energy substitution in rural India', Land Economics, Vol. 76, No. 2, pp.213-232.

KIFCON (1994) Kenya Indigenous Forest Conservation Programme: Phase 1 Report, Nairobi, Kenya.

Matshe, I. and Young, T. (2004) 'Off-farm labour allocation decisions in small-scale rural households in Zimbabwe', Agricultural Economics, Vol. 30, pp.175-186.

Mitchell, N. (2004) 'The exploitation and disturbance history of Kakamega forest, Western Kenya', in Bleher, B. and Dalitz, H. (Eds): Bielefelder Ökologische Beiträge, Band 20, BIOTA East Report No. 1, Gesellschaft für Forschung und Technologie, Universität Bielefeld, p.77

Mogaka, H., Simons, G., Turpie, J., Emerton, L. and Karanja F. (2001) Economic Aspects of Community Involvement in Sustainable Forest Management in Eastern and Southern Africa, IUCN Policy Brief, Nairobi, Kenya.

Newman, C. and Canagarajah, R.S. (2000) Gender, Poverty and Nonfarm Employment in Ghana and Uganda, World Bank Policy Research Unit, The World Bank, Washington, DC.

Sadoulet, E. and de Janvry, A. (1995) Quantitative Development Policy Analysis, The Johns Hopkins University Press, London.

Singh, I., Squire, L. and Strauss, J. (1986) 'The basic model: theory, empirical results, and policy conclusions', in Singh, I., Squire, L. and Strauss, J. (Eds): Agricultural Household Models, The Johns Hopkins University Press, Baltimore.

Shively, G., Fisher, M. and Buccola, S. (2005) 'Activity choice, labour allocation and forest use in Malawi', Land Economics, Vol. 81, No. 4, pp.503-517.

Warner, K. (2000) 'Forestry and sustainable livelihoods', Unasylva, Vol. 51, pp.3-12.

Woldehanna, T. (2000) Economic Analysis and Policy Implications of Farm and Off-Farm Employment: A Case Study in Tigray Region of Northern Ethiopia, Unpublished $\mathrm{PhD}$ Dissertation, Wageningen University, Wageningen, The Netherlands.

World Development Report (2008) Agriculture for Development, The World Bank, Washington, DC.

Zellner, A. (1962) 'An efficient method for estimating seemingly unrelated regression and tests for aggregation bias', Journal of American Statistics Association, Vol. 57, pp.348-368. 